\title{
A case of ecthyma gangrenosum in immunocompromised patient
}

\section{Rhizlane Chaoui, Asmae Rasso, Selma El Kadiri, Zakia Douhi, Sara Elloudi, Hanane Baybay, Fatima Zahra Mernissi}

\author{
Department of Dermatology, University Hospital Hassan II, Fez, Morocco
}

Corresponding author: Dr. Rhizlane Chaoui, E-mail: chaoui.rhizlane@gmail.com

A 80 -year-old female with pancytopenia from chemotherapy for Hodgkin lymphoma developed one week ago fever and a painless red maculeunder her left breast.

Physical exam revealed an ulcerating lesion with central necrosis, mesuring $4 \mathrm{~cm}$ in diametersurrounded by a halo of erythemaunder left breast (Fig. 1).

The patient was started on broad-spectrum antibiotics. Blood and lesion cultures revealed Pseudomonas Aeruginosa confirming the diagnosis of ecthyma gangrenosum. The initial empirical treatment was switched to parenteral third generation cephalosporins.

Ecthyma gangrenosum (EG) is a rare skin infection classically associated with Pseudomona aeruginosabacteraemia.Clinically, it progresses sequentially from maculopapular lesion to haemorrhagic bulla and then to necroting ulcers surrounded by an erythematous halo.It usually affects immunocompromised patients (neutropaenia,hematological malignancies) and rarely occurs in immunocompetent subjects. The diagnosis is generally made based on the clinical appearance and evolution of the lesions along with a positive blood or wound cultures.

Antibiotic therapy with spectrum for Pseudomonas aeruginosa includes aminoglycosides, third- and fourth-generation cephalosporins, $\beta$-lactam antibiotics, and broad-spectrum penicillins.

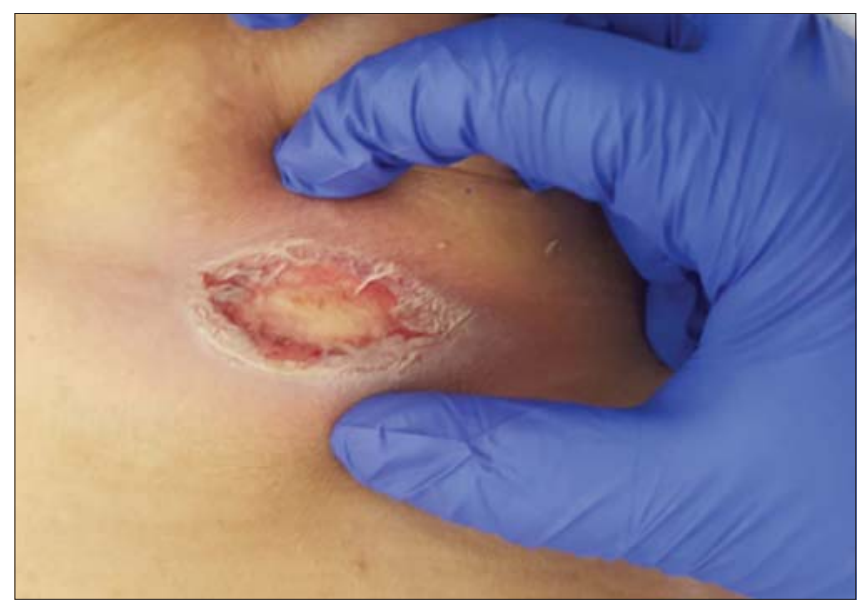

Figure 1: Ulcerating lesion with central necrosis, mesuring $4 \mathrm{~cm}$ in diameter surrounded by a halo of erythema under left breast.

Prognosis depends on the degree of immunosuppression and on the host.

\section{Consent}

The examination of the patient wasconductedaccording to the Declaration of Helsinki principles.

The authorscertifythatthey have obtained all appropriate patient consent forms. In the form the patient(s) has/have givenhis/her/their consent for his/her/their images and otherclinical information to bereported in the journal. The patients understandthattheirnames and initialswill not bepublished and due efforts willbe made to concealtheiridentity, but anonymitycannotbeguaranteed.

Copyright by Rhizlane Chaoui, et al. This is an open access article distributed under the terms of the Creative Commons Attribution License, which permits unrestricted use, distribution, and reproduction in any medium, provided the original author and source are credited.

Source of Support: Nil, Conflict of Interest: None declared.

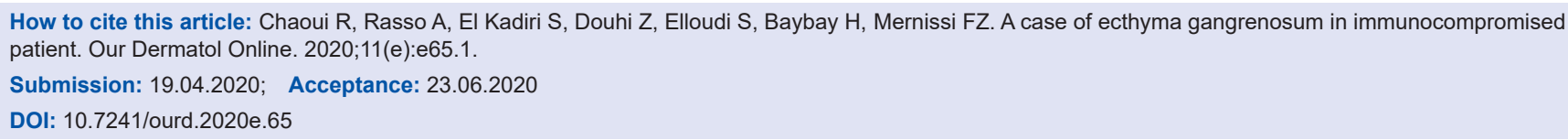

